\title{
Study on Shear Properties of the Soil-rock Mixture
}

\author{
$\mathrm{B} \mathrm{Li}^{*}$ \\ CCCC FIRST HIGHWAY CONSULTANTS CO., LTD, No 63,2th, keji Road, xi’an, Shanxi, 71005, China
}

\begin{abstract}
In order to study the shear properties of the soil-rock mixture, a large-scale indoor direct shear test is used to test the shear strength $(\tau)$ of SRM under different positive pressures, and calculates the internal friction angle $(\varphi)$ and cohesive force $(c)$ according to the molar theory. The effects of soil-rock ratio, gradation, maximum particle size, moisture content, and compaction on the shear properties of the soil-rock mixtures are studied. The results show that as the soil-rock ratio decreases, the $\tau$ and $\varphi$ of the SRM increase, while the $\mathrm{c}$ increases first and then decreases, and reaches the maximum peak when the soil-rack ratio is 40:60. As the maximum particle size increases, the $\tau$ and $\varphi$ of the SRM increase, while the $c$ decreases. With the increase of the moisture content, the $\tau$, $\varphi$ and $c$ of the SRM all increase first and then decrease, and reach the maximum peaks when the moisture content is $10.5 \%, 10 \%$, and $12 \%$, respectively. With the increase of compaction, the $\tau, \varphi$ and $c$ of SRM all increase. The effect of gradation on $\tau, \varphi$ and $c$ is small.
\end{abstract}

\section{Introduction}

A large number of the soil-rock mixtures (SRM) are used as subgrade fillers during road construction. As an important bearing structure, the subgrade directly affects the performance of the subgrade [1]. SRM is composed of gravel or rock as aggregate and clay or sand as filler. It has the characteristics of large particle size differences and uneven composition, and its mechanical properties change law is more complicated [2-4].

Shear performance is an important engineering characteristic index for the subgrade filler and a basic parameter for the stability analysis of high-filled subgrade [5]. Guo et al. pointed out that the shear strength of SRM was composed of the strength of fines and coarse materials, and the coarse material content of $30 \%$ and $70 \%$ were the two limit points of three similar properties of soil, coarse-grained soil, and gravel [6]. Donaghe et al. tested the mechanical properties of SRM through the triaxial compression test, and analysed the stress-strain curve, pore pressure-strain curve and effective stress path trend chart [7]. Rodriguez et al. measured the strength and deformation characteristics of SRM through the hydraulic cylinder test [8]. The shear performance of SRM is closely related to the mechanical properties of the soil and rock, the soil-rock ratio, and the shape of crushed rock [5]. Shi et al. analysed the stress change law of the soil-rock mixtures under different rock contents and different confining pressures through cyclic dynamic load triaxial tests [9]. Miller et al. conducted a triaxial compression test on coarse-grained soil composed of clay and coarse sand, and found that as the coarse-grained content increases, its cohesive force gradually decreases, and the internal friction angle increases rapidly when the coarse particle content is $50 \%$ to $70 \%$ [10-11]. Lv tested the shear strength of SRM at different soil-rock ratios by direct shear method [12]. Patwardhan and Shakoor et al. studied the influence of rock content on the shear characteristics of SRM, and the results showed that as the rock content increased, the shear strength of SRM continues to increase, and the unconfined compressive strength decreased slowly [1315]. Wang et al. used triaxial tests to study the influence of confining pressure, rock content, and compactness on the shear strength of SRM [16]. S Wang et al. studied the effect of gravel size on the shear performance of SRM through indoor triaxial tests [17]. Y Zhang et al. studied the strength and deformation characteristics of soilbreccia mixtures and soil-rock interactions, and monitored the movement of breccia during shearing [18].

In summary, there are many studies on the shear properties of SRM and its influencing factors. However, most of them focus on the influence of rock content on the shear properties, and some of them involve compaction and moisture content. The study of the gradation and maximum particle size on the shear performance of SRM has not been reported. In view of this, this paper uses a large-scale indoor direct shear test to test the shear strength $(\tau)$, internal friction angle $(\varphi)$, and cohesion $(c)$ of SRM, and studies the influence of soil-rock ratio, gradation, maximum particle size, moisture content and compaction on the shear performance of SRM.

\section{Test materials and methods}

\subsection{Test materials}

"1bingabc@163.com 
The particle composition and physical technical of the SRM used in the test are shown in Table 1 and Table 2. The fine grain is sandy gravel and the coarse grain is quartzite. The SRM was divided into two parts by the
$4.75 \mathrm{~mm}$ sieve: fine-grained materials (soil) with the particle $\leq 4.75 \mathrm{~mm}$ and coarse-grained materials (rock) with the particle $>4.75 \mathrm{~mm}$. Mixtures with different soilrock ratios were mixed according to the test.

Table 1 Particle composition of SRM

\begin{tabular}{cccccccccc}
\hline Sieve size $/ \mathrm{mm}$ & 40.0 & 20.0 & 10.0 & 5.0 & 2.0 & 1.0 & 0.5 & 0.25 & 0.075 \\
Passing rate $/ \%$ & 100.0 & 88.2 & 71.7 & 52.9 & 29.1 & 22.9 & 11.4 & 3.1 & 2.0 \\
\hline
\end{tabular}

Table 2 Physical and technical properties of SRM

\begin{tabular}{ccccc}
\hline $\begin{array}{c}\text { Coefficient of non- } \\
\text { uniformity } C_{u}\end{array}$ & $\begin{array}{c}\text { Curvature } \\
\text { coefficient } C c\end{array}$ & Liquid limit /\% & Plastic limit /\% & Plasticity index \\
\hline 14.6 & 1.5 & 31 & 19 & 12 \\
$\geq 5$ & $1 \sim 3$ & - & - & - \\
\hline
\end{tabular}

\subsection{Test methods}

The large-scale direct shear instrument VJT2780A is used for consolidation first and then quick shear test. The specific test steps are as follows:

Step 1: Prepare SRM samples. Configure and weigh 4 SRM samples for testing in accordance with the requirements of large-scale direct shear tests. The basic unit of each group of samples is $4500 \mathrm{~g}$. Calculate the corresponding material for each file, add the corresponding water, mix the stuffy material overnight, and prepare about 5 units ( 5 barrels) for each group. It is compacted in two steps. Firstly, half of the sample is poured into the test mould. After the treatment is uniform, the compaction hammer is used to strike the compaction until it reaches the required depth. Then add another half of sample, spread and tamp until the sample reaches the score line height. Permeable plates and steel plates are placed on the sample at the same level as the outer edge of the straight shear box. (Due to the low compaction power of artificial compaction, a compaction degree of $90.5 \%$ is generally sufficient.)

Step 2: Check the instrument and the team parameters.

Step 3: Install the test box and insert the fixing pin. Install the normal displacement sensor, and the upper shear box just contacts the normal displacement sensor.

Step 4: Turn on the desktop computer, start the program control software, and enter the test parameters;

Step 5: Apply a vertical pressure of $0.1,0.2,0.3$, and $0.4 \mathrm{MPa}$, respectively.

Step 6: Pull out the fixing pin and start the shear test, the shear rate is $3 \mathrm{~min} / \mathrm{min}$;

Step 7: Read the test data after the shear test is completed.

\subsection{Test scheme}

The changes of shear strength $\tau$, internal friction angle $\varphi$ and cohesion c of SRM were studied, and the influence of soil-rock ratio, gradation, maximum particle size, moisture content and compaction were analysed.

(1) The particles above $4.75 \mathrm{~mm}$ are regarded as rock particles, the particles below $4.75 \mathrm{~mm}$ are regarded as soil particles, the maximum particle size is $40 \mathrm{~mm}$, and 7 kinds of soil-rock ratios are designed, as shown in Table 3. The compaction degree of the test piece was $90.5 \%$ and the moisture content was $12 \%$. The tests were performed under four different normal stresses of $100 \mathrm{kPa}$, $200 \mathrm{kPa}, 300 \mathrm{kPa}$, and $400 \mathrm{kPa}$. Study the effect of soilrock ratio on the shear characteristics of SRM.

(2) The soil-rock ratio is 50:50, the maximum particle size is $40 \mathrm{~mm}$, the compaction is $90.5 \%$, and the moisture content is $12 \%$. Design three types of gradation, as shown in Table 4, to investigate the effect of gradation on shear characteristics of SRM.

(3) The soil-rock ratio was 50:50, the compaction was $90.5 \%$, and the moisture content was $12 \%$. The designed maximum particle sizes are $10 \mathrm{~mm}, 20 \mathrm{~mm}$, and $40 \mathrm{~mm}$, as shown in Table 5, to investigate the effect of maximum particle sizes on shear characteristics of SRM.

(4) The soil-rock ratio is 50:50, the maximum particle size is $40 \mathrm{~mm}$, and the compaction degree is $90.5 \%$. The moisture content was set to $8 \%, 10 \%, 12 \%$, and $14 \%$, to investigate the effect of moisture content on shear characteristics of SRM.

(5) The soil-rock ratio is 50:50, the maximum particle size is $40 \mathrm{~mm}$, and the moisture content is $12 \%$. Experiments were performed at three different compaction degrees $\mathrm{K}$ of $85 \%, 90.5 \%$, and $96 \%$, to investigate the effect of compaction on the shear characteristics of SRM.

Table 3 Soil-rock test plan

\begin{tabular}{cccccc}
\hline Soil-rock ratio & $20-40$ & $10-20$ & $5-10$ & $2-5$ & $\leq 2$ \\
\hline $80: 20$ & 5 & 7 & 8 & 36 & 44 \\
$70: 30$ & 7 & 11 & 12 & 32 & 38
\end{tabular}




\begin{tabular}{cccccc}
$60: 40$ & 10 & 14 & 16 & 27 & 33 \\
$50: 50$ & 13 & 17 & 20 & 23 & 27 \\
$40: 60$ & 15 & 21 & 24 & 18 & 22 \\
$30: 70$ & 18 & 24 & 28 & 13 & 17 \\
$20: 80$ & 20 & 28 & 32 & 9 & 11 \\
\hline
\end{tabular}

Table 4 Gradation composition test plan

\begin{tabular}{cccccc}
\hline Gradation type & $20-40$ & $10-20$ & $5-10$ & $2-5$ & $\leq 2$ \\
\hline Gradation 1 & 13 & 17 & 20 & 23 & 27 \\
Gradation 2 & 20 & 15 & 15 & 25 & 25 \\
Gradation 3 & 30 & 10 & 10 & 25 & 25 \\
\hline
\end{tabular}

Table 5 Maximum particle size test plan

\begin{tabular}{cccccc}
\hline Maximum particle $(\mathrm{mm})$ & $20-40$ & $10-20$ & $5-10$ & $2-5$ & $\leq 2$ \\
\hline 10 & 0 & 0 & 50 & 23 & 27 \\
20 & 0 & 23 & 27 & 23 & 27 \\
40 & 13 & 17 & 20 & 23 & 27 \\
\hline
\end{tabular}

\section{Results and discussions}

\subsection{Effect of soil-rock ratio}

Follow the soil-rock ratio test plan in Table 3. The fixed maximum particle diameter was $40 \mathrm{~mm}$, the compaction was $90.5 \%$, and the moisture content was $12 \%$. The results are shown in Figure 1 and Figure 2.

It can be seen from Figure 1 that when the normal stress is the same, the shear strength $\tau$ of SRM increases with the increase of the soil-rock ratio, and the two are approximately linear. The larger the normal stress is, the larger the value of $\tau$. For the rock content will affect the structure of SRM. When the rock content is small, the rock particles are completely filled with soil particles and held apart by the soil particles. The rock particles are far away from each other, forming a suspended and dense structure. The shear strength is mainly affected by the properties of the fine particles (soil) and the moisture content. When the rock content is $50 \sim 70 \%$, the rock particles are completely filled with soil particles, and the rock particles are close to each other, forming a dense skeleton structure. The shear strength is mainly composed of the cohesion force of the coarse particles and the cohesion of the fine particles. When the rock content exceeds $70 \%$, the voids between rock particles cannot be completely filled with soil particles, forming a skeleton void structure, and the voids increase with the increase of rock content. The shear strength mainly comes from the mutual embedding of coarse particles Squeeze effect, the effect of fine particles is very small, and its properties are close to that of rock fill roadbed. Therefore, as the soil-rock ratio decreases, the value of $\tau$ increases.

From Figure 2, as the rock content increases, the internal friction angle $\varphi$ increases, and the cohesion $\mathrm{c}$ changes in a convex curve, with a peak at $60 \%$ of the rock content $(38.60 \mathrm{kPa})$, and then the value of $\mathrm{c}$ decreases. This is because the structure of SRM will affect the internal cohesion and friction. When the rock content is less than $50 \%$, the cohesion and friction mainly come from the interaction between soil particles. When the rock content is $50 \sim 70 \%$, the SRM has a dense skeleton structure. The coarse aggregate on the shear surface plays a dominant role in the skeleton. Under the action of shear force, the soil is first destroyed, and the coarse aggregates contact each other to make them sticky. The cohesion and the internal friction angle are improved. When the rock content is more than $70 \%$, the SRM has a dense skeleton structure, the porosity increases and the fine particles decrease greatly, the $\varphi$ value increases, and the $c$ value decreases.

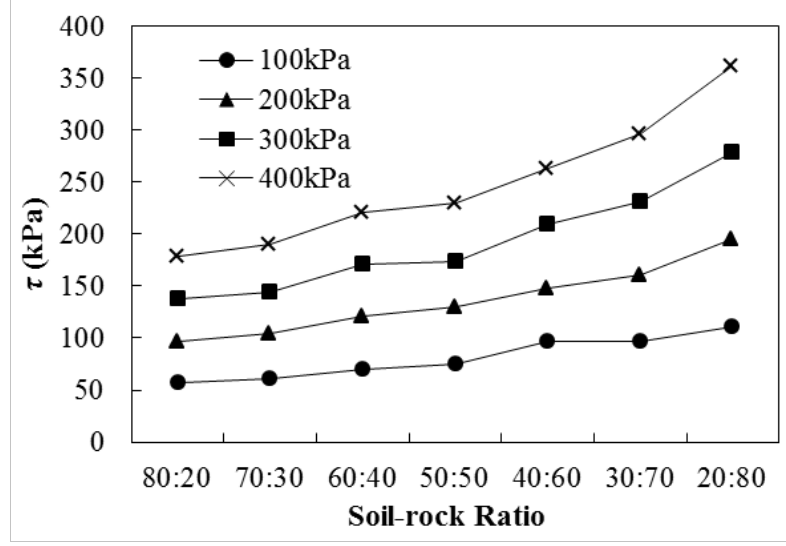

Figure 1 Effect of soil-rock ratio on $\tau$ 


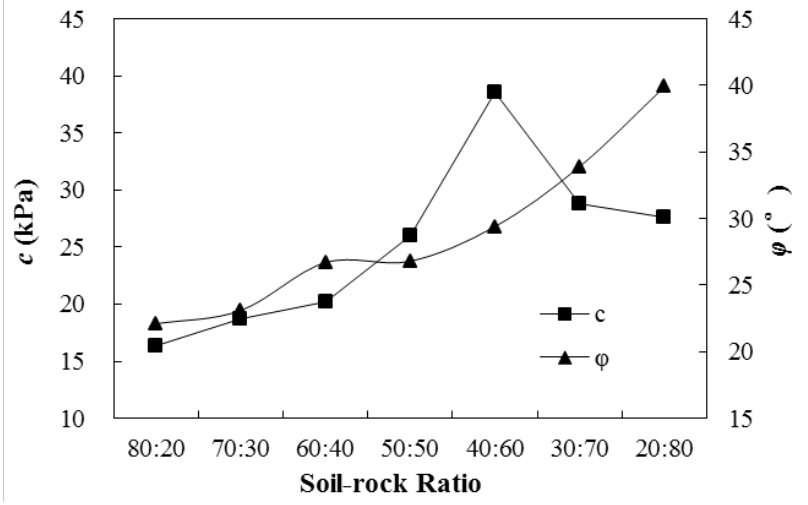

Figure 2 Effect of soil-rock ratio on $\varphi$ and $c$

\subsection{Effect of gradation}

Change the gradation; follow the particle size composition in Table 4. The soil-rock ratio is 50:50, the maximum particle size is $40 \mathrm{~mm}$, the compaction is $90.5 \%$, and the moisture content is $12 \%$. The results are shown in Figure 3 and Figure 4. Results show that the gradation change has little effect on the shear strength, internal friction angle, and cohesion of the SRM.

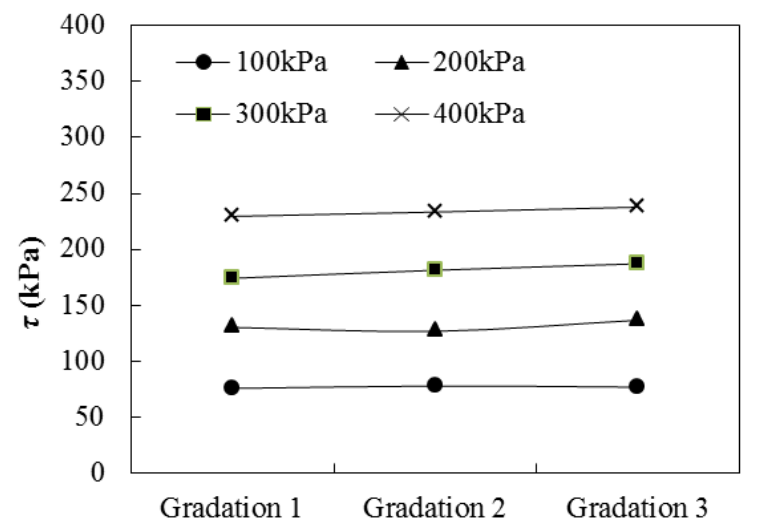

Figure 3 Effect of gradation on $\tau$

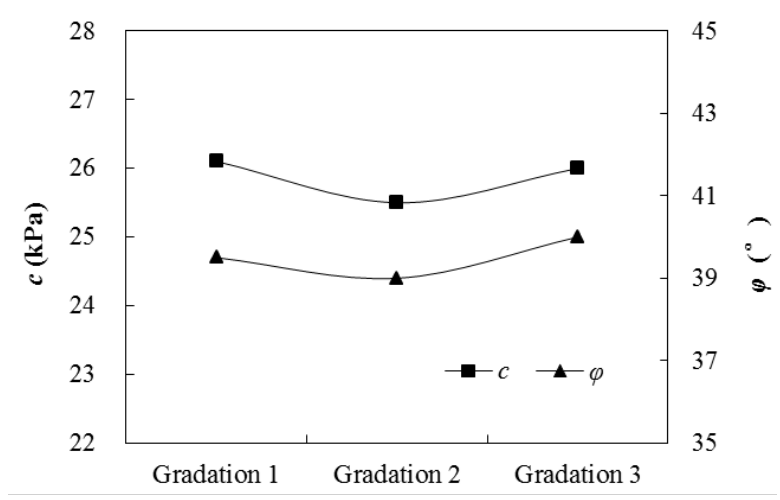

Figure 4 Effect of gradation on $\varphi$ and $c$

\subsection{Effect of maximum particle size}

Follow the particle size composition in Table 5. The fixed soil-rock ratio was 50:50, the compaction was $90.5 \%$, and the moisture content was $12 \%$. The results are shown in Figure 5 and Figure 6.
It can be seen from Figure 5 that when the normal stress is the same, the shear strength $\tau$ increases with the increase of the maximum particle size, and the shear strength of $D_{\max }=40 \mathrm{~mm}$ is 1.29 times that of $D_{\max }=$ $10 \mathrm{~mm}$. The larger the normal stress is, the larger the value of $\tau$. From Figure 6, with the increase of the maximum particle size, the internal friction angle $\varphi$ of the SRM increases, while the cohesion $c$ decreases. For with the particles increasing, the pinching force and friction between the coarse particles are increased, and the contact between the internal fine particles and the large particles becomes smaller, and the adhesion effect becomes worse.

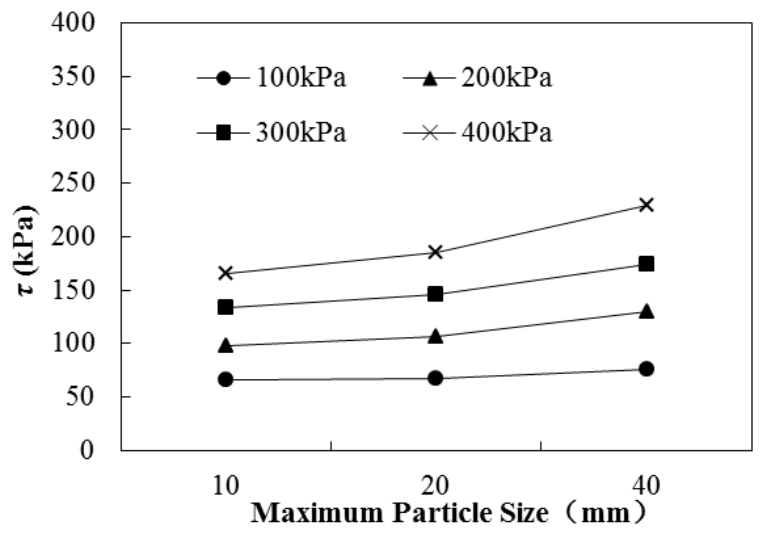

Figure 5 Effect of maximum particle size on $\tau$

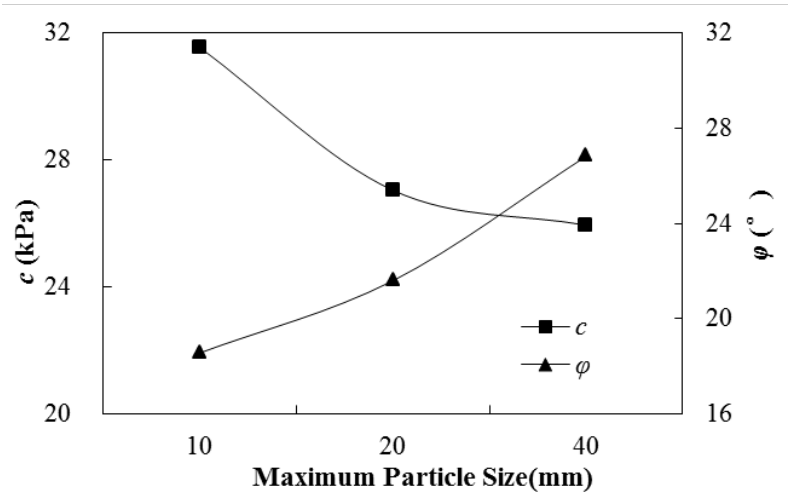

Figure 6 Effect of maximum particle size on $\varphi$ and $c$

\subsection{Effect of moisture content}

The soil-rock ratio is 50:50, the maximum particle size is $40 \mathrm{~mm}$, and the compaction degree is $90.5 \%$. The moisture content was set to $8 \%, 10 \%, 12 \%$, and $14 \%$, results are shown in Figure 7 and Figure 8.

It can be seen from Figure 7 that when the normal stress is the same, the shear strength $\tau$ of the SRM increases first and then decreases with increasing moisture content, and reaches a peak when the moisture content is $10.5 \%$. The larger the normal stress is, the larger the value of $\tau$. Classical water film theory [19] believes that too high or too low moisture content is not conducive to the tight arrangement of the granular materials, squeeze each other, and adversely affect the strength of the mixture. 


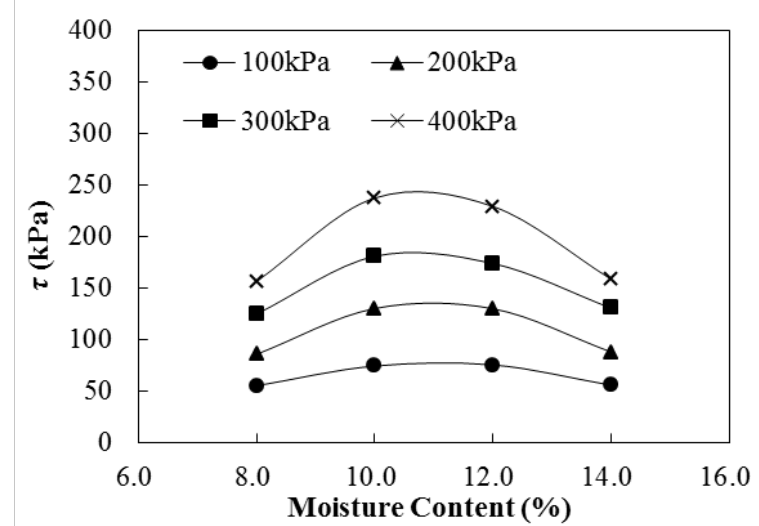

Figure 7 Effect of moisture content on $\tau$

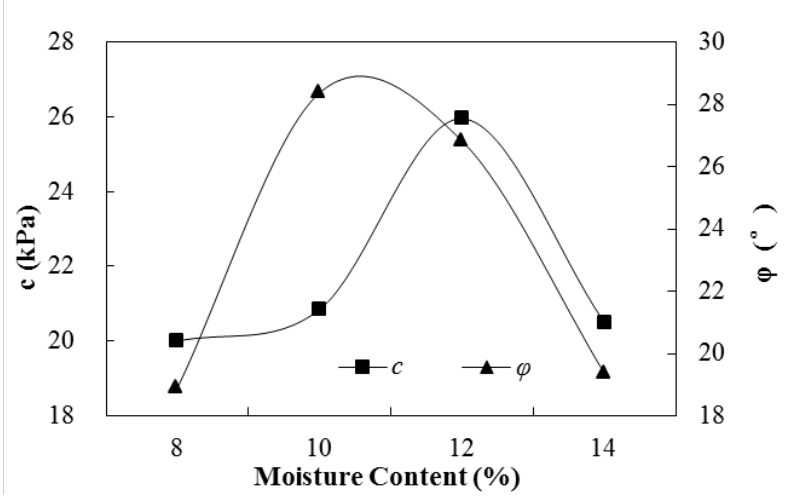

Figure 8 Effect of moisture content on $\varphi$ and $c$

\subsection{Effect of on compaction degree}

The soil-rock ratio is 50:50, the maximum particle size is $40 \mathrm{~mm}$, the moisture content is $12 \%$, and the tests were performed in compaction degrees $\mathrm{K}$ of $85 \%, 90.5 \%$, and 96\%. The results are shown in Figure 9 and Figure 10.

When the normal stress is the same, the shear strength, internal friction angle, and cohesive force of the SRM all increase with the increase of the compaction degree. As the particles get closer, the squeezing force and cohesive force increase. Similarly, the larger the normal stress is, the larger the values of $\tau, \varphi$ and $c$.

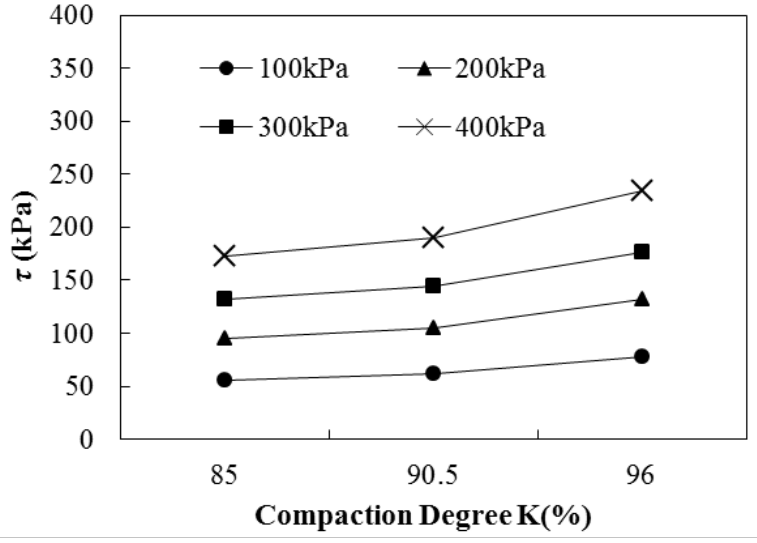

Figure 9 Effect of compaction degree on $\tau$

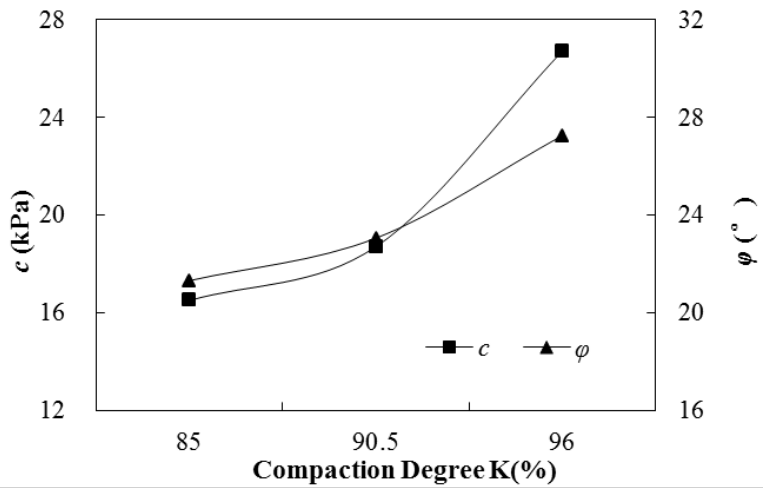

Figure 10 Effect of compaction degree on $\varphi$ and $c$

\section{Conclusions}

1. As the soil-rock ratio decreases, the shear strength $\tau$ of the SRM increases, the internal friction angle $\varphi$ increases, the cohesive force $c$ increases first and then decreases, reaching a peak when the soil-rock ratio is 40:60.

2 . The effect of gradation on the shear strength $\tau$, the internal friction angle $\varphi$ and the cohesive force $c$ values is small.

3. As the maximum particle size increases, the shear strength $\tau$ of SRM increases, the internal friction angle $\varphi$ increases, and the cohesion $c$ decreases. Therefore, reasonably increasing the particle size can improve its shear strength;

4. With the increase of the moisture content, the shear strength $\tau$, the internal friction angle $\varphi$, and the cohesion $c$ all increase and then decrease, and reach the maximum peak when the moisture content is $10.5 \%, 10 \%$, and $12 \%$, respectively;

5. With the increase of the compaction degree, the shear strength $\tau$, the internal friction angle $\varphi$ and the cohesive force $c$ all gradually increase. Therefore, increasing compaction is an effective way to improve the shear performance of soil-rock mixed subgrades.

\section{References}

1. Li X X. (2008) Application of construction technology of earth-rock mixed roadbed in highway engineering. Technology and market, 25(07):93-94. 
2. Xu W.J., Li C.Q., Zhang H.Y., (2015), DEM analyses of the mechanical behavior of soil and rock-mixture via the $3 \mathrm{D}$ direct shear test, Geomechanics and Engineering, 9(6), 815-827,

3. Qiang W, Xin-li H U, Ying X U, et al.(2018) Investigation on compaction characteristics and meso-mechanism of the soil-rock mixture with soft rock blocks. Journal of ZheJiang University (Engineering Science), 52(12): 2295-2305.

4. Zhao Y, Liu Z.(2018) Study of material composition effects on the mechanical properties of soil-rock mixtures. Advances in Civil Engineering, 2018.

5. Wu S F, CAI H, Wei Y Q, Xiao J Z, Yan J.(2019) Study on shear mechanism and component characteristics of shear strength of earth-rock mixture. Chinese journal of geotechnical engineering ,41(S2):230-234.

6. Guo Q G.(1979) Discussion on engineering characteristics and classification of coarse grained soil. Water conservancy and hydropower technology (06):55-59.

7. Donaghe R T, Torrey V h. i.(1985) Strength and deformation properties of earth - rock mixtures. Earth.

8. Rodriguez R F, Nicieza C G, Gayarre F L, et al.(2015) Application of hydraulic cylinder testing to determine the geotechnical properties of groundfilled DAMS. Geomechanics \& Engineering, ,9 (4) : 483-498.

9. Shi Z J, Zeng Y W, Liu F R.(2008) Experimental study on dynamic rebound modulus of earth-rock mixed roadbed filler. Journal of water conservancy and construction engineering, 16(03): 138-143+154.

10. MILLER, E A, SOWERS G f. (1958) The strength characteristics of soil - aggregate mixtures [J]. Journal of Highway Research Board Bulletin, 1957183, 16-23.

11. KAWAKAMI H, ABE h.(1970) Shear characteristics of saturated gravelly clays. The Transactions of the Japanese Society of Civil Engineers, 2 (2) : 295298.

12. Lv X F, Zhou h.(2018) soil-rock mixture shear strength measurement based in situ borehole pressure-shear tests. Journal of Geophysics \& Engineering, 15(5):2221-2234.

13. PATWARDHAN A S, RAO J S,GAIDHANE R b. (1970) Interlocking effects and shearing of hold of boulders and large size particles in a matrix of fines on the basis of large scale direct shear tests, Proc 2 nd Southeast AsianConference on Soil Mechanic. Singapore, 265-273.

14. SHAKOOR A, COOK B d. (1990) The effect of The size, and shape on The engineeringproperties of $A$ compacted silty clay. Bulletin of The Association of Engineering Geologists, 27:245-253.

15. Zhang M C, Liu X R, Wang P, Du L B.(2019) Shear characteristics and meso failure mechanism of mud rock mixtures with different rock contents . Journal of civil and Environmental Engineering (Chinese and English), ,41 (06): 17-26

16. Wang P.(2017) PFC simulation of large triaxial test and micromechanical properties of earth-rock mixture. Chongqing university.

17. Wang S, Ji T, Xue Q, et al.(2019) Deformation and Failure Characteristics of Soil-Rock Mixture considering Material Composition and Random Structure. Advances in Materials Science and Engineering.

18. Zhang Y.(2017) Study on Strength, Deformation Characteristics and Interaction between Soil and Rock of Soil-Rock Mixture. Chemical Engineering Transactions, 59: 985-990.

19. Zhao M H, Liu X P, Peng W X.(2007) Application of water film theory to suction in unsaturated soil . Rock and soil mechanics, (07):1323-1327. 